\title{
Utilização de cobertura comestível na conservação pós-colheita de minimilho minimamente processado
}

\author{
Use of edible coverage in post-harvest preservation of minimally processed baby corn \\ Valéria Aparecida Vieira QUEIROZ1^, Érica Aguiar MORAES², Luciano Rodrigues QUEIROZ3, \\ Flávio Dessaune TARDIN ${ }^{1}$, Estefânia de Oliveira GUEDES, \\ Israel Alexandre PEREIRA FILHOํㅜ, Cláudio Teixeira LOMBARDI ${ }^{5}$
}

\begin{abstract}
Resumo
Minimilhos obtidos das cultivares de milho Vivi, híbrido simples de endosperma doce em fase experimental, e AG 1051, híbrido duplo comercial, comum, foram revestidos com cobertura comestível de fécula de mandioca a 2 e $4 \%$ e armazenados a $5{ }^{\circ} \mathrm{C}$. Um tratamento controle, sem revestimento, foi utilizado nas mesmas condições. Foram realizadas análises físico-químicas a cada três dias, durante nove dias, e de perda de massa, diariamente, a partir do terceiro até o décimo segundo dia. Observou-se variação na acidez, no pH e nos teores de Sólidos Solúveis Totais (SST) das amostras ao longo do período de armazenamento. A cobertura com fécula de mandioca não influenciou na acidez e no pH do minimilho obtido da cultivar de milho Vivi, no final do armazenamento, porém elevou a acidez da cultivar AG 1051. De um modo geral, o revestimento com cobertura de fécula de mandioca foi eficiente na preservação da massa de minimilho, no armazenamento refrigerado a $5^{\circ} \mathrm{C}$. O desempenho da cultivar experimental Vivi foi similar ao da cultivar comercial AG 1051 para as variáveis perda de massa (controle e cobertura a 4\%) e acidez (cobertura a 2 e 4\%) e melhor para a variável SST (cobertura a 2 e $4 \%$ ).

Palavras-chave: Zea mays; fécula de mandioca; acidez; sólidos solúveis; perda de massa.
\end{abstract}

\begin{abstract}
Baby-corns were obtained from maize cultivars Vivi, simple hybrid of sweet endosperm in experimental phase and AG 1051 commercial double hybrid, common, were coated with cassava starch edible coverage, at 2 and $4 \%$, and stored at $5{ }^{\circ} \mathrm{C}$. A control treatment, without coating, was used under the same conditions. Physicochemical analyses were conducted every three days for nine days; and daily analyses of mass loss were conducted from the third to the twelfth day. It was observed a variation in acidity, in $\mathrm{pH}$, and in the total soluble solids contents of the samples during storage. There was no influence by the cassava starch coverage on the acidity and on the $\mathrm{pH}$ of the babycorns obtained from cultivar Vivi at the end of storage; however, the acidity of cultivar AG 1051 increased. In general, it can be said that the coating process using cassava starch was effective in preserving the mass loss of baby-corn in cold storage of $5{ }^{\circ} \mathrm{C}$. The performance of the experimental cultivar Vivi was similar to that of the commercial cultivar AG1051 for parameters such as mass loss (control and coverage at $4 \%$ ) and acidity (coverage at 2 and 4\%). On the other hand, it was better for SST parameter (coverage at 2 and $4 \%$ ).

Keywords: Zea mays; cassava starch; acidity; soluble solids; mass loss.
\end{abstract}

\section{Introdução}

Minimilho é a "espiga jovem de milho" colhida dois a três dias após a exposição dos cabelos ou estilo-estigmas (PEREIRA FILHO; GAMA; FURTADO, 1998; ALMEIDA et al., 2005) cujo valor nutricional é comparado ao das demais hortaliças. Segundo Tomé et al. (2001), o minimilho obtido da cultivar de milho doce apresenta, em média, a seguinte composição: $1,9 \%$ de proteína, $0,1 \%$ de gordura, $6,8 \%$ de carboidrato, $0,9 \%$ de cinzas e $0,8 \%$ de fibras.

A Tailândia domina o mercado mundial de minimilho tanto com o produto in natura, como enlatado (TOMÉ, 2002).
No Brasil, sua produção é, ainda, pouco explorada, embora o mercado seja promissor interna e externamente (RODRIGUES; DA SILVA; MORI, 2004). Entretanto, o mercado internacional exige avaliações qualitativas rigorosas, o que impõe à indústria, um maior controle de qualidade de seus produtos (TOMÉ, 2002). A manutenção da qualidade demanda o desenvolvimento de tecnologias que considerem os aspectos fisiológicos, tecnológicos, nutricionais microbiológicos e sensoriais do alimento.

Vários estudos têm sido conduzidos a respeito do manejo cultural do minimilho no Brasil, como por exemplo, genótipos

Recebido para publicação em 30/7/2008

Aceito para publicação em 29/6/2009 (003738)

${ }^{1}$ Departamento de Nutrição e Saúde, Universidade Federal de Viçosa - UFV, Av. PH Rolfs, s/n, Campus Universitário, CEP 36570-000, Viçosa - MG, Brasil,

E-mail: erica_moraes12@hotmail.com,valeria@cnpms.embrapa.br

2 Embrapa Milho e Sorgo, Rod. MG 424, Km 65, CP 151, CEP 35701-970, Sete Lagoas - MG, Brasil, E-mail: valeria@cnpms.embrapa.br, tardin@cnpms.embrapa.br, israel@cnpms.embrapa.br

3 Departamento de Fitotecnia, Universidade Federal de Viçosa - UFV, E-mail: lrodqueiroz@yahoo.com.br

${ }^{4}$ Faculdade de Biomedicina, Universidade José do Rosário Vellano - UNIFENAS, Belo Horizonte - MG, Brasil, E-mail: estefania.guedes@yahoo.com.br

${ }^{5}$ Laboratório de Zootecnia e Nutrição Animal, Universidade Estadual do Norte Fluminense - UFV, Av. Alberto Lamego, n. 2000, CEP 28013-602, Campos dos Goytacazes - RJ, Brasil, E-mail: lombardi@uenf.br

${ }^{*}$ A quem a correspondência deve ser enviada 
de milho, visando identificar aqueles mais apropriados para obtenção de minimilho (PEREIRA FILHO; GAMA, 2001; von PINHO et al., 2003; RODRIGUES; DA SILVA; MORI, 2004). Porém, as condições necessárias para manutenção das características adequadas, propiciando a comercialização de um produto de alta qualidade, ainda não estão totalmente esclarecidas.

Produtos de origem vegetal, como o minimilho, têm vida de prateleira e qualidade pós-colheita afetadas em consequência das reações catabólicas que ocorrem, acarretando a perda do produto (LANA, 2000 apud HOJO et al., 2007). De acordo com Carvalho (2002), durante três dias de armazenamento de minimilho minimamente processado, a redução de peso do produto pode chegar a $6,8 \%$, em consequência da perda de água na evaporação e respiração, com redução concomitante da qualidade.

Com o intuito de aumentar a vida útil e retardar a senescência desses produtos, alguns tratamentos associados à refrigeração têm sido empregados, como a utilização de embalagens protetoras e o revestimento com películas comestíveis. Esses artifícios visam controlar a perda de massa pela transpiração e reduzir as trocas gasosas pela respiração (VICENTINI; CEREDA, 1999; TOMÉ et al., 2001). As coberturas comestíveis são películas formadas sobre a própria superfície do alimento e, ultimamente, têm sido bastante exploradas no revestimento de frutas e hortaliças frescas (AZEREDO, 2003). Essas coberturas funcionam como barreira às trocas gasosas e à perda de água, melhoram a aparência e ajudam a conservar a integridade estrutural e as propriedades mecânicas, levando ao aumento da vida útil dos alimentos (RIBEIRO et al., 2005).

Materiais oriundos do amido, da celulose ou mesmo do colágeno, aplicados diretamente nos alimentos, podem ser utilizados para este fim, podendo ser consumidos ainda com a película formada no processo (BOBBIO, P. A.; BOBBIO, F. O., 1984). Devido à formação de camadas transparentes e resistentes que agem como barreira à perda de água além de proporcionar brilho e bom aspecto a frutas e hortaliças, a fécula de mandioca é um ingrediente que tem sido considerado adequado para a elaboração de coberturas comestíveis (HOJO et al., 2007). O uso de coberturas de fécula de mandioca em concentrações variando de 1 a $5 \%$ em morangos foi eficiente na minimização da perda de massa e aumento de cinco vezes na vida útil da fruta (HENRIQUE; CEREDA, 1999).

O efeito de revestimentos comestíveis sobre o aumento da vida útil de minimilho minimamente processados são ainda desconhecidos, com grande potencial para estudo. Dessa forma, este trabalho objetiva avaliar o efeito da aplicação de cobertura comestível de fécula de mandioca na conservação pós-colheita de minimilho minimamente processado.

\section{Material e métodos}

\subsection{Procedência das amostras}

O trabalho foi conduzido na área experimental da Embrapa Milho e Sorgo, em Sete Lagoas - MG, na safra 2007/2008. Foram utilizadas as cultivares de milho Vivi, híbrido simples de endosperma doce, experimental desenvolvido pela Embrapa Milho Sorgo, e o híbrido duplo comum, AG 1051, cultivados no espaçamento de $80 \mathrm{~cm}$ entrelinhas e densidade de 180.000 plantas por hectare por ocasião da colheita.

A adubação de plantio foi de $300 \mathrm{~kg} \cdot \mathrm{ha}^{-1}$ da formula 8-28-16 + Zn e a cobertura com $60 \mathrm{~kg} \cdot \mathrm{ha}^{-1}$ de nitrogênio, realizada aos 25 dias após a germinação das plântulas. Foi feita uma aplicação do herbicida Primestra Gold para manter a cultura limpa até a colheita que foi realizada dois dias após a emergência dos cabelos ou estilo-estigmas.

\subsection{Coleta e preparo das amostras}

A colheita foi realizada no período da manhã, sendo as amostras de minimilho acondicionadas em caixa de isopor com gelo e, em seguida, encaminhadas ao Laboratório de Grãos Armazenados, onde foram lavadas em água corrente e depois imersas em solução de hipoclorito de sódio a $100 \mathrm{mg} . \mathrm{L}^{-1}$ por 15 minutos para sanitização da parte externa do material. Em seguida, os minimilhos foram despalhados com auxílio de faca inoxidável, selecionados entre 8 e $12 \mathrm{~cm}$ de comprimento, novamente lavados em água corrente e imersos em solução de hipoclorito de sódio de $20 \mathrm{mg} . \mathrm{L}^{-1}$ por mais 15 minutos. Para evitar o escurecimento enzimático, o material foi ainda submergido em solução de ácido cítrico a 1\% por 5 minutos e, logo após, centrifugado, em centrífuga manual, para retirada do excesso de solução. As coberturas comestíveis, nas concentrações de 2 e de $4 \%$, foram preparadas por meio de aquecimento das suspensões de água e fécula de mandioca a $70^{\circ} \mathrm{C}$ até geleificação. As amostras de minimilho foram centrifugadas, imersas nas suspensões de fécula de mandioca já resfriadas à temperatura ambiente e acomodadas sobre bandejas plásticas até secagem do filme com auxílio de um ventilador. Após essa etapa, foram acondicionadas em embalagens de polietileno tereftalato (PET) e armazenadas, por 12 dias, sob refrigeração a $5^{\circ} \mathrm{C}$ em câmara BOD com controle de temperatura. Um lote de minimilho sem revestimento ( $0 \%$ de fécula de mandioca) foi acondicionado e armazenamento nas mesmas condições como tratamento controle.

Nos dias 0; 3; 6; e 9, amostras correspondentes a três minimilhos foram retiradas para as avaliações da acidez titulável, do $\mathrm{pH}$ e dos sólidos solúveis totais. As análises de perda de massa foram realizadas a cada dia a partir do terceiro dia de armazenamento até o $12^{\circ}$ dia.

\subsection{Composição centesimal}

A composição centesimal do minimilho foi determinada no início do experimento para caracterização das cultivares. $\mathrm{O}$ teor de água foi determinado em estufa com circulação forçada de ar a $60{ }^{\circ} \mathrm{C}$ até massa constante. $\mathrm{O}$ teor de nitrogênio foi definido pelo método de Kjeldahl (ASSOCIATION..., 2002) e a proteína bruta foi calculada utilizando-se o fator de conversão 6,25, expressa em porcentagem. A determinação do extrato etéreo foi realizada em extrator Soxhlet, utilizando-se como solvente éter de petróleo. O teor de cinzas foi obtido por meio da incineração a $550{ }^{\circ} \mathrm{C}$ por cinco horas. Em seguida, foram resfriadas e pesadas (ASSOCIATION..., 2002). O teor de carboidratos foi determinado 
por diferença, subtraindo-se de $100 \%$ a soma dos resultados obtidos nas análises anteriores. As fibras insolúveis (celulose, lignina e hemicelulose) foram determinadas pelo método de van Soest (SILVA, 1990).

\subsection{Acidez titulável, pH e sólidos solúveis}

A acidez total titulável foi obtida por titulação com $\mathrm{NaOH} 0,01 \mathrm{~N}$, segundo metodologia estabelecida pela AOAC (ASSOCIATION..., 2002) e expressa em porcentagem de ácido málico. O pH e o teor de Sólidos Solúveis Totais (SST), expresso em ${ }^{\circ}$ Brix, foram determinados pelos métodos propostos pela AOAC (ASSOCIATION..., 2002).

\subsection{Perda de massa}

A massa das amostras foi determinada pesando-se, diariamente, em balança eletrônica com precisão de 0,001 g, as embalagens contendo as miniespigas. A perda de massa foi calculada por meio da Equação 1:

$[($ massa inicial - massa a cada intervalo de tempo $) /($ massa inicial $)] \times 100$. (1)

\subsection{Delineamento experimental análise estatística}

Foi utilizado o delineamento experimental inteiramente casualizado, em arranjo fatorial $2 \times 3 \times 4$ (cultivares $\times$ concentração da cobertura $\times$ tempo de armazenamento) para as análises físicoquímicas e $2 \times 3 \times 10$ para a variável perda de massa, em três repetições. Os dados experimentais foram submetidos à análise de variância. As interações significativas pelo teste " $F$ " foram desdobradas e as médias comparadas através do teste de Tukey ao nível de significância de $5 \%$ de probabilidade. A variável perda de massa foi avaliada por análise de regressão.

\section{Resultados e discussão}

\subsection{Composição centesimal}

Houve pequena variação entre a composição centesimal dos minimilhos provenientes dos milhos Vivi e AG 1051 (Tabela 1). Tomé (2002) avaliou a composição centesimal das cultivares de milho Elisa (Pioneer), de endosperma doce, e C929 (Cargill), de endosperma comum, e encontrou, respectivamente, os seguintes resultados: 90,69 e 90,82\% de água, 1,59 e 1,39\% de proteína, 0,18 e $0,16 \%$ de extrato etéreo, 0,67 e $0,67 \%$ de fibra bruta, 6,56 e $6,64 \%$ de carboidrato e 0,38 e $0,32 \%$ de cinzas. Dessa forma, os resultados apresentados no presente trabalho foram semelhantes aos da literatura supracitada, com a maior diferença sendo evidenciada para os valores de fibra. Esse fato foi devido, possivelmente, à diferença entre os métodos utilizados na análise de fibra, ou seja, Fibra em Detergente Neutro (FDN) e fibra bruta (TOMÉ, 2002).

\subsection{Acidez titulável (AT)}

Houve interação significativa entre genótipo (Vivi e AG 1051) e tipo de cobertura utilizada $(0 ; 2$; e $4 \%$ de fécula de mandioca) (Figura 1). Observa-se que, para a cultivar AG 1051, os minimilhos revestidos com cobertura a 2 e a $4 \%$ exibiram maior acidez durante o armazenamento que aqueles sem revestimento e, para a cultivar Vivi, houve diferença entre o tratamento a 2 e a $4 \%$. Apenas no tratamento sem cobertura comestível houve diferença entre as cultivares com menor percentual de acidez para o AG 1051.

Verifica-se que, para ambas as cultivares, houve elevação significativa da acidez do início (tempo zero) até o terceiro dia de armazenamento com subsequente redução, do terceiro ao sexto dia, para concentrações iguais às observadas no tempo zero (Figura 2a). Resultado semelhante foi verificado por Hojo et al. (2007) no armazenamento de pimentões recobertos com fécula de mandioca a 3,5; 4,0; e 4,5\%, por 10 dias. Apenas no terceiro e no nono dia houve diferença significativa entre as cultivares, ao longo do período de armazenamento. No último dia, a cultivar doce exibiu acidez igual à do tempo zero e a cultivar AG 1051, mais elevada.

Para os minimilhos sem cobertura, não houve alteração da acidez ao longo do período de armazenamento e o efeito das coberturas a 2 e a $4 \%$ de fécula de mandioca sobre a acidez titulável foi semelhante (Figura 2b). No terceiro dia de armazenamento, notou-se diferença significativa entre minimilhos sem revestimento (0\%) e revestidos com cobertura a 2 e a $4 \%$ de fécula. A partir do dia três, houve redução da

Tabela 1. Composição centesimal (b.u. ${ }^{\star}$ ) dos minimilhos obtidos das cultivares de milho, AG 1051 e Vivi. Sete Lagoas - MG, 2008.

\begin{tabular}{lrr}
\hline Componentes (\%) & \multicolumn{2}{c}{ Cultivares } \\
\cline { 2 - 3 } & AG 1051 & Vivi \\
\hline Água & 89,66 & 89,43 \\
Proteínas & 1,85 & 1,68 \\
Extrato etéreo & 0,26 & 0,28 \\
Cinzas & 0,42 & 0,39 \\
Fibras (FDN) & 2,56 & 2,77 \\
Carboidratos & 5,25 & 5,45 \\
\hline
\end{tabular}

*b.u., base úmida.

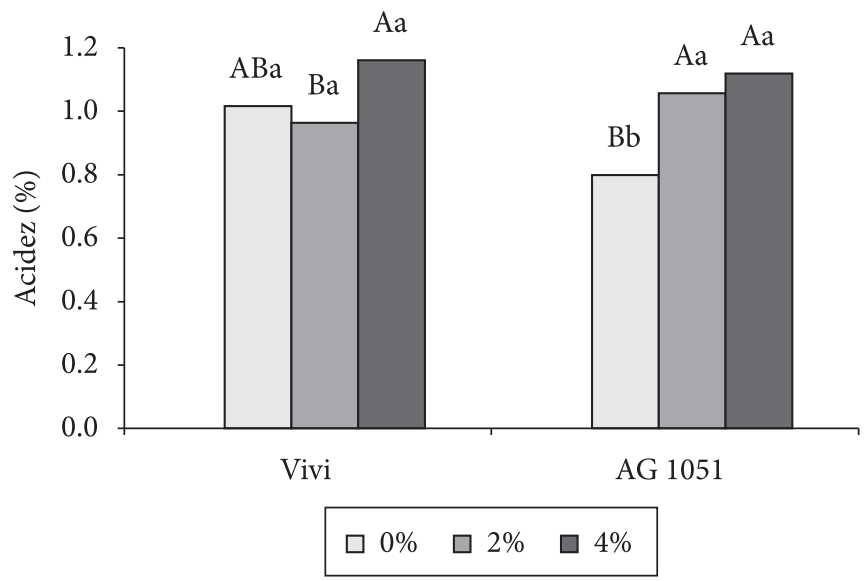

Figura 1. Acidez titulável (\% ácido málico) no armazenamento de minimilho das cultivares Vivi e AG 1051 revestidas com cobertura de fécula de mandioca a $0 ; 2$; e $4 \%$. Médias seguidas pela mesma letra maiúscula, em cada cultivar, entre os diferentes tipos de cobertura ou minúscula, em cada tipo de cobertura entre as cultivares, não diferem entre si ao nível de 5\% de probabilidade. 
acidez para os tratamentos 2 e 4\%, alcançando percentual igual ao determinado nos minimilhos não revestidos. A acidez dos minimilhos sem revestimento e daqueles cobertos a $2 \%$ de fécula, foram iguais à acidez no tempo zero. No entanto, o minimilho revestido a $4 \%$ apresentou percentual de acidez maior que no início do experimento.

\section{$3.3 p H$}

Para a variável $\mathrm{pH}$, não houve interação significativa entre a cultivar e a concentração da solução de cobertura e entre esta última e o tempo, apenas entre a cultivar e o tempo (Figura 3). Verificou-se elevação dos valores de $\mathrm{pH}$ a partir do tempo zero até o terceiro e o sexto dia para as cultivares AG 1051 e Vivi, respectivamente, seguido de redução significativa para concentrações iguais às do tempo inicial para ambas as cultivares. Hojo et al. (2007) observaram comportamento semelhante em pimentões revestidos com solução de fécula de mandioca a 3,5; 4,0; e 4,5\%. Foi observada diferença de $\mathrm{pH}$,
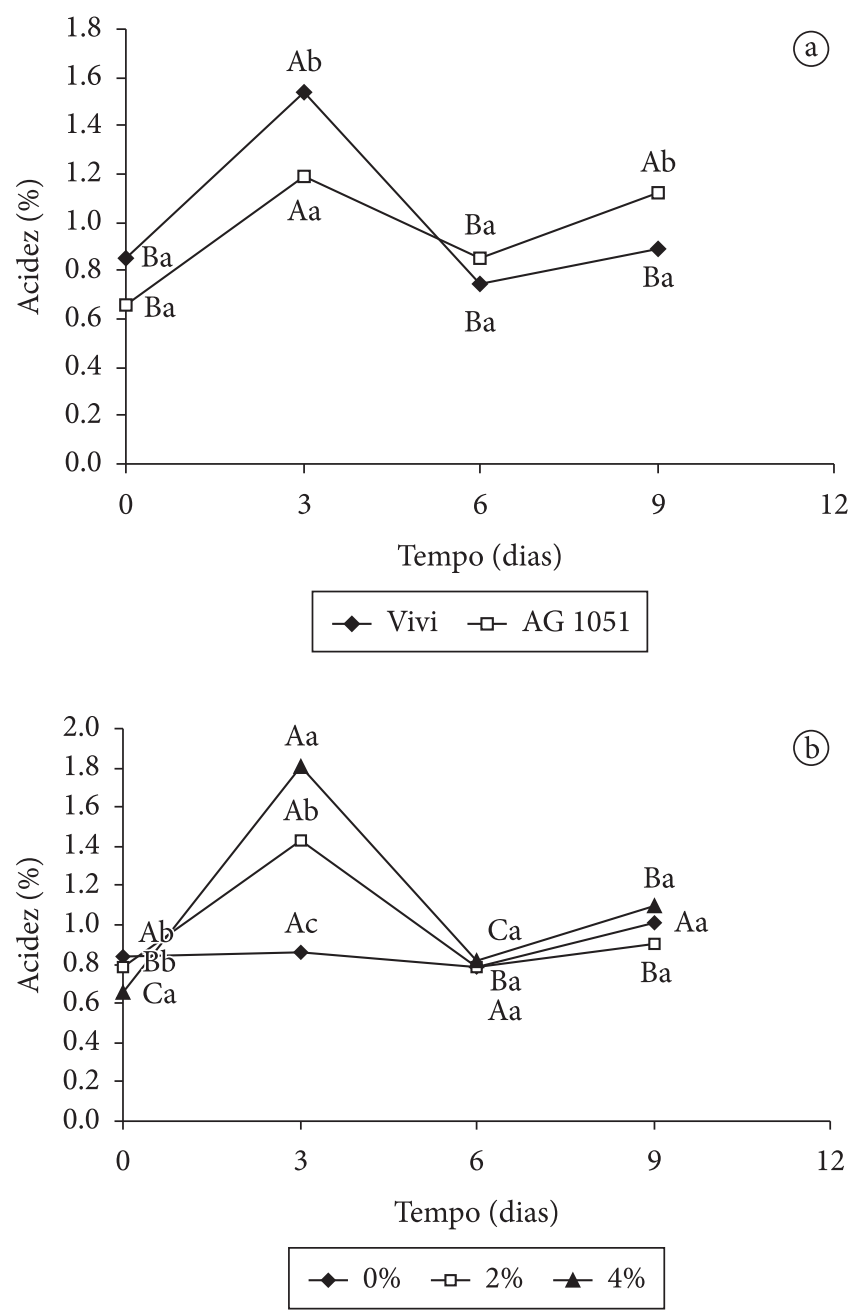

Figura 2. Acidez titulável (\% ácido málico) de minimilho, no armazenamento refrigerado por nove dias. a) cultivares Vivi e AG 1051; b) espigas revestidas com cobertura de fécula de mandioca a 0 ; 2; e $4 \%$. Médias seguidas pela mesma letra maiúscula, em cada cultivar, entre os diferentes tipos de cobertura ou minúscula, em cada tipo de cobertura entre as cultivares, não diferem entre si ao nível de $5 \%$ de probabilidade. entre as cultivares, apenas no sexto dia de armazenamento, em que a cultivar Vivi exibiu maior valor de $\mathrm{pH}$.

\subsection{Sólidos Solúveis Totais (SST)}

Ocorreu interação entre cultivares e tipo de cobertura no teor de Sólidos Solúveis Totais (SST), expresso em ${ }^{\circ}$ Brix, no armazenamento de minimilho por nove dias (Figura 4). A cobertura a $4 \%$ de fécula de mandioca propiciou teor mais alto de SST em relação ao tratamento controle (sem cobertura) para ambas as cultivares. Ao contrário, Damasceno et al. (2003) observaram, no armazenamento de tomate, que no tratamento sem cobertura de fécula de mandioca o teor de SST foi maior que naqueles recobertos a 2 e $3 \%$.

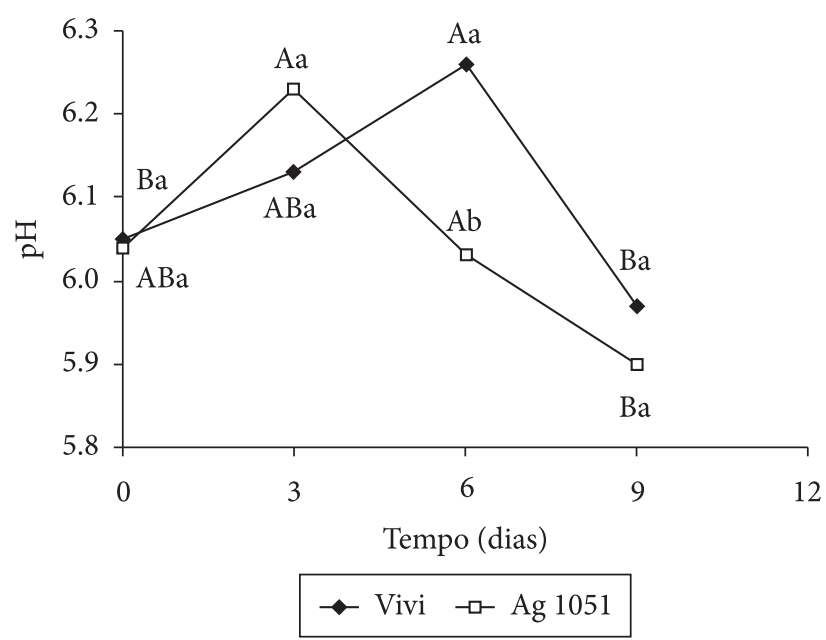

Figura 3. pH de minimilho das cultivares Vivi e AG 1051, no armazenamento refrigerado por nove dias. Médias seguidas pela mesma letra maiúscula, ao longo do tempo ou minúscula, entre cultivares em cada tempo, não diferem entre si ao nível de $5 \%$ de probabilidade.

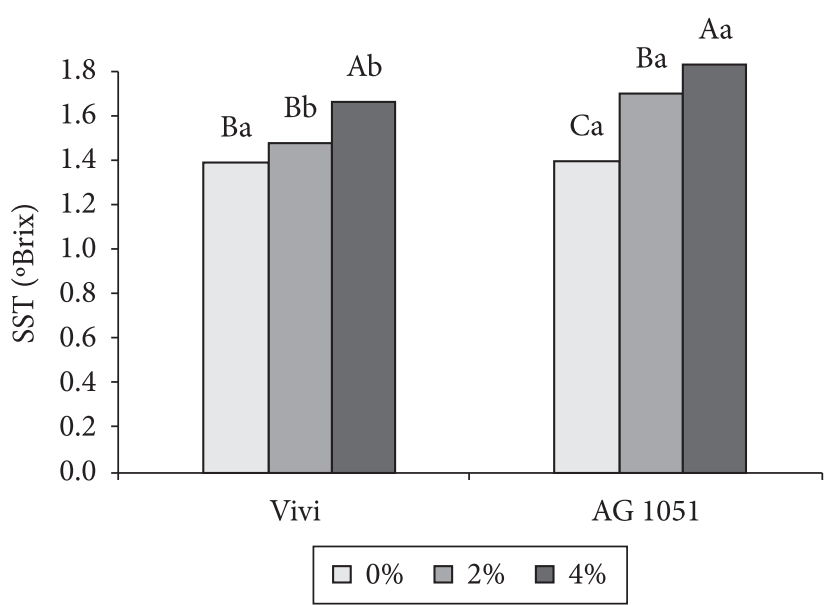

Figura 4 . Sólidos solúveis totais ( ${ }^{\circ}$ Brix) de minimilho das cultivares Vivi e AG 1051 revestidos com cobertura de fécula de mandioca a 0; 2 ; e $4 \%$. Médias seguidas pela mesma letra maiúscula, em cada cultivar, entre os diferentes tipos de cobertura ou minúscula, em cada tipo de cobertura entre as cultivares, não diferem entre si ao nível de $5 \%$ de probabilidade. 
Para os minimilhos sem revestimento, os teores de sólidos solúveis foram iguais para ambas as cultivares. No entanto, esses teores foram significativamente menores para as amostras da cultivar Vivi revestidas tanto com cobertura a 2 quanto a $4 \%$.

Do tempo zero até o sexto dia de armazenamento houve variação nos teores de SST para ambas as cultivares e para os três tipos de cobertura utilizados (Figura 5). Resultado semelhante foi apresentado por Lemos et al. (2007) em pimentões revestidos com cobertura de fécula de mandioca nas concentrações de 3, 4 e $5 \%$ e armazenados por até 20 dias a 10 e $24,5^{\circ} \mathrm{C}$.

Do tempo inicial (zero) até o terceiro dia, houve aumento nos SST sendo evidenciadas diferenças entre os três tipos de cobertura em sentido crescente ao nível de fécula contida. No entanto, a partir do dia três, verificou-se redução nos teores de SST em todas as cultivares e tipos de cobertura, chegando ao final do armazenamento com teores abaixo dos iniciais. Esse resultado corrobora com o apresentado por Damasceno et al.
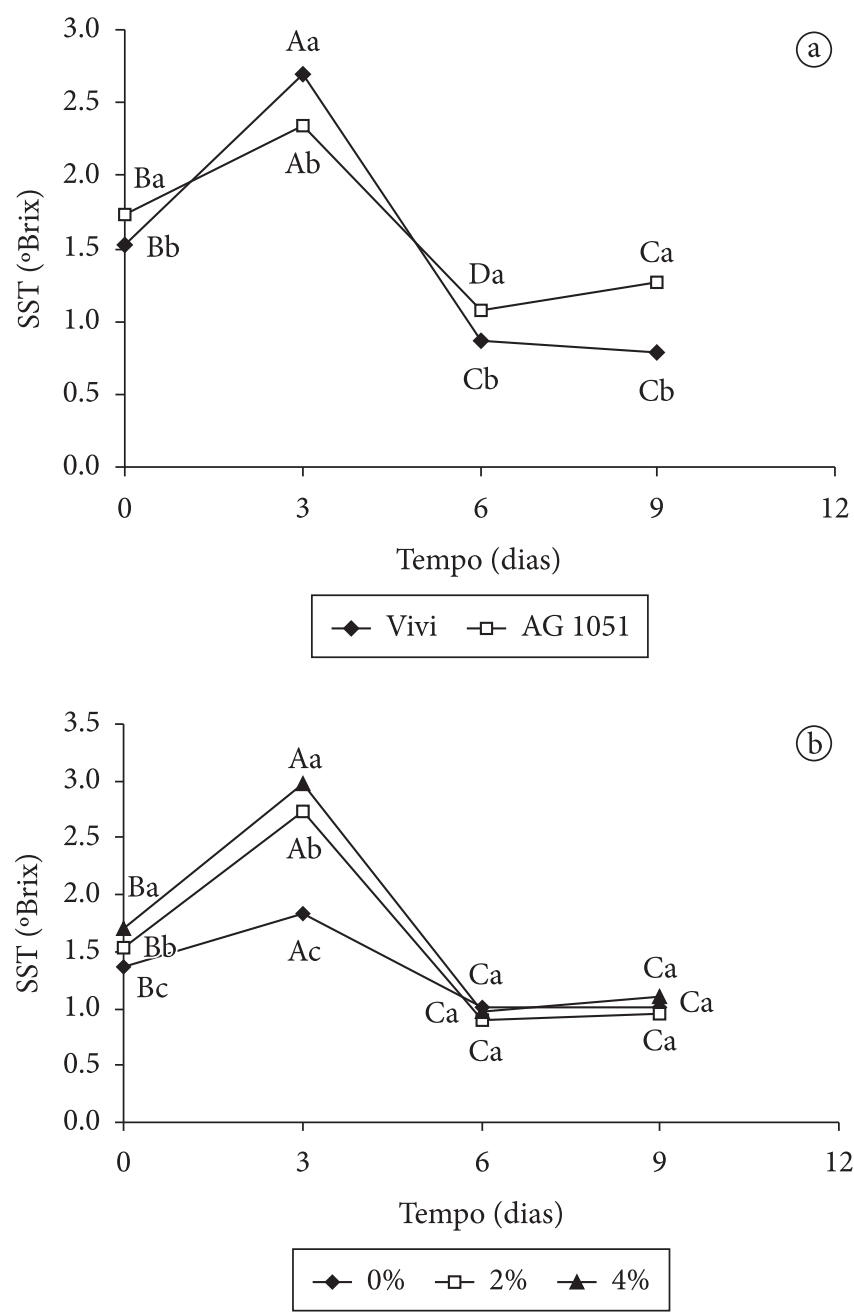

Figura 5. Sólidos solúveis totais ( ${ }^{\circ}$ Brix) de minimilho, no armazenamento refrigerado por nove dias. a)cultivares Vivi e AG 1051; e b)espigas revestidas com cobertura de fécula de mandioca a 0 ; 2 ; e $4 \%$. Médias seguidas pela mesma letra maiúscula, ao longo do tempo ou minúscula, entre tipos de cobertura em cada tempo, não diferem entre si ao nível de $5 \%$ de probabilidade.
(2003) no final do armazenamento de tomates revestidos por fécula de mandioca a $0 ; 2$; e $3 \%$.

Depois do sexto dia, os três tipos de cobertura igualaramse em relação aos teores de SST, possivelmente devido a uma redução e estabilização no metabolismo dos tecidos vegetais após este dia. Vicentini, Castro e Cereda (1999) não observaram efeitos significativos da cobertura à base de fécula de mandioca sobre o teor de SST em pimentões cultivar Valdor.

As diferenças observadas entre os resultados dos diversos trabalhos desenvolvidos pelos autores supracitados podem ser atribuídas a valores distintos empregados nas variáveis do processo como, \% de amido das coberturas, diferenças nos tecidos vegetais das espécies analisadas, temperatura e tempo de armazenamento.

\subsection{Perda de massa (\%)}

Houve interação significativa entre genótipo e tipo de cobertura sobre a perda de massa de minimilho armazenado sob refrigeração a $5{ }^{\circ} \mathrm{C}$ por 12 dias (Figura 6). Verificou-se que, para a cultivar Vivi, o tratamento a $4 \%$ foi significativamente diferente dos demais levando à menor perda de massa das amostras. As coberturas a 2 e a $4 \%$ de fécula de mandioca proporcionaram maior retenção de massa dos minimilhos cultivar AG 1051, mostrando efeito positivo desse tipo de tratamento no armazenamento desse produto. A análise entre as cultivares revelou que apenas no tratamento com cobertura a $2 \%$ houve diferença significativa na perda de massa entre as duas cultivares analisadas, com menor perda para a AG 1051. De um modo geral, observou-se que a cobertura de fécula de mandioca foi eficiente na preservação da massa de minimilho no armazenamento refrigerado. Fakhouri et al. (2007) também observaram que uvas Crimson armazenadas sem cobertura comestível apresentaram maior perda de água do primeiro ao $22^{\circ}$ dia de armazenamento, em relação àquelas tratadas com

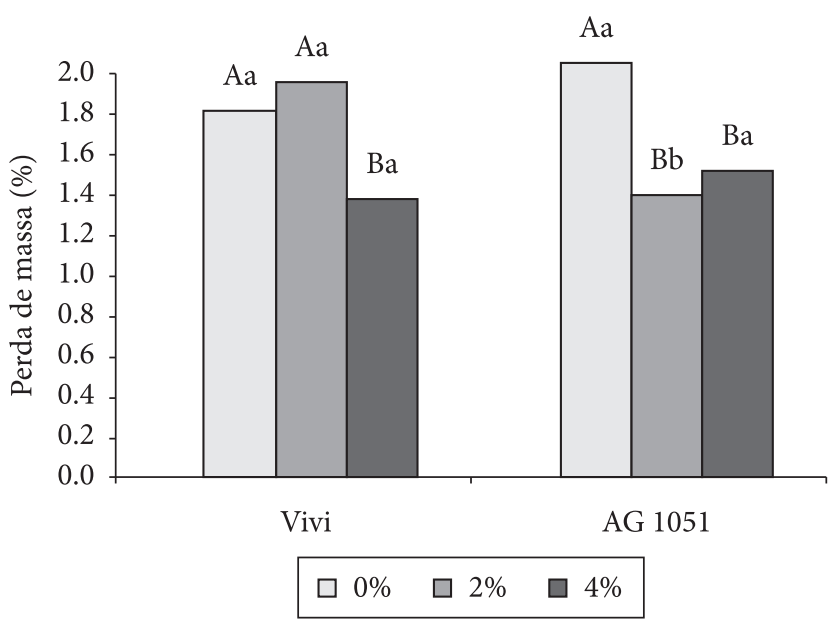

Figura 6. Perda de massa no armazenamento de minimilho das cultivares Vivi e AG 1051 revestidas com cobertura de fécula de mandioca a $0 ; 2$; e $4 \%$. Médias seguidas pela mesma letra maiúscula, entre os tipos de cobertura em cada cultivar ou minúscula, entre as cultivares em cada cobertura, não diferem entre si ao nível de $5 \%$ de probabilidade. 
coberturas de gelatina com amidos nativos de trigo, sorgo, batata e arroz, chegando a perder aproximadamente 14\% de água ao final do experimento. Ao contrário, Hojo et al. (2007) concluíram que biofilme de fécula de mandioca, nas concentrações de 3,5; 4,0; e 4,5\%, não foi efetivo na conservação de pimentão Ikeda, armazenado sob condições ambientais. Temperaturas mais elevadas favorecem a transpiração nos tecidos vegetais e consequente aumento da perda de massa, sendo recomendado o armazenamento das hortaliças sob temperaturas mínimas, que condicionem a máxima conservação pós-colheita (PAULL, 1999). Este fato pode ter influenciado nos resultados descritos por Hojo et al. (2007), em que utilizaram temperatura de $22 \pm 1{ }^{\circ} \mathrm{C}$ no armazenamento dos pimentões, não tendo, a cobertura de fécula de mandioca, sido suficiente para inibir significativamente a perda de massa do produto. Temperatura inferior $\left(5^{\circ} \mathrm{C}\right)$ foi utilizada no armazenamento

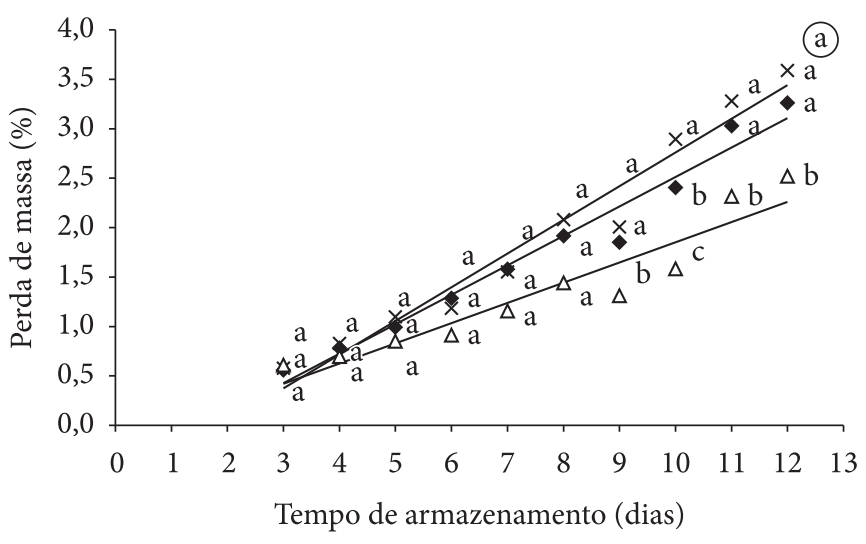

\begin{tabular}{|cccc|}
\hline $0 \%$ & $y=0,2979 x-0,4675$ & $\times 2 \%$ & $y=0,3407 x-0,6467$ \\
& $R 2=0,968$ & & $R 2=0,9622$ \\
$\Delta 4 \%$ & $y=0,2042 x-0,1921$ & \\
& R2 $=0,8997$ & \\
\hline
\end{tabular}

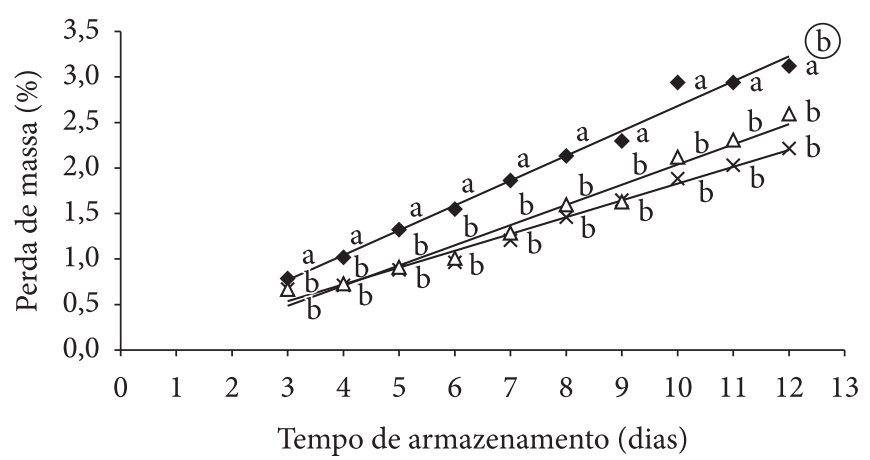

$$
\begin{array}{cccc}
\qquad 0 \% & y=0,2731 x-0,0514 & \times 2 \% & y=0,1847 x-0,0183 \\
& R^{2}=0,9849 & & R^{2}=0,985 \\
\Delta 4 \% & y=0,2219 x-0,1802 & & \\
& \mathrm{R}^{2}=0,9715 &
\end{array}
$$

Figura 7. Perda de massa de minimilho, no armazenamento refrigerado por 12 dias. a) cultivares Vivi e AG 1051; e b) espigas revestidas com cobertura de fécula de mandioca a $0 ; 2$; e $4 \%$. Médias, entre os tipos de cobertura $(0 ; 2 ;$ e $4 \%)$, seguidas de mesma letra em cada tempo não diferem entre si ao nível de $5 \%$ de probabilidade. dos minimilhos e das uvas Crimson, nos trabalhos supracitados. Neres et al. (2004) avaliaram o efeito da temperatura de armazenamento e da embalagem plástica na perda de massa fresca de jiló, cv. 'Tinguá'. Os frutos foram armazenados em três temperaturas, $25 \pm 2{ }^{\circ} \mathrm{C}$ (ambiente); 13 e $5^{\circ} \mathrm{C}$, embalados e não embalados em sacos de polietileno de baixa densidade (PEBD) com $80 \mu \mathrm{m}$ de espessura. Os resultados do trabalho mostraram que a perda de massa diária, nos frutos armazenados sem a proteção do $\mathrm{PEBD}$, a $25 \pm 2{ }^{\circ} \mathrm{C}, 13$ e $5^{\circ} \mathrm{C}$ foi de $2,37,0,91$ e $0,84 \%$, respectivamente. Nos frutos embalados, as perdas foram de 0,079, 0,037 e 0,029\% respectivamente, ratificando, desta forma, a influência da temperatura de armazenamento sobre a perda de água de hortaliças.

Observou-se aumento linear significativo na perda de massa das amostras durante os 12 dias de armazenamento (Figura 7a). Para a cultivar Vivi, as diferenças na perda de massa entre os tratamentos começou a ocorrer apenas no dia nove. A partir desse dia, o tratamento com cobertura a $4 \%$ de fécula de mandioca diferiu dos demais, proporcionando maior retenção da massa dos minimilhos, já, a cobertura a $2 \%$ não diferiu do controle no final do armazenamento. Por outro lado, na cultivar AG 1051, a diferença entre o tratamento controle e aqueles submetidos à cobertura a 2 e a $4 \%$ ficou evidenciada desde o terceiro dia e foi pronunciando-se até o $12^{\circ}$ dia.

Do início até o final do armazenamento, houve perda de massa, para o minimilho obtido da cultivar de milho doce Vivi, de 3,26; 3,59; e 2,52\%, respectivamente, para as coberturas 0,2 e $4 \%$ de fécula e de 3,$12 ; 2,21$; e 2,59\% para o minimilho obtido da cultivar de milho AG 1051 (Figura 7b). Esses resultados diferem daqueles apresentados por Tomé (2002) em que foi observada perda de massa de 0,92; 0,93; e 0,97\% em minimilho das cultivares de milho-pipoca, doce e comum, respectivamente, no armazenamento por 12 dias sob refrigeração a $5{ }^{\circ} \mathrm{C}$. Esse fato, possivelmente, seja devido ao acondicionamento das espigas em bandejas de isopor coberta com filme de PVC e não em embalagem de tereftalato conforme realizado no presente trabalho.

\section{Conclusões}

No final do armazenamento, a acidez e o pH de minimilho não foram influenciados pelo revestimento com cobertura de fécula de mandioca, mas houve redução dos sólidos solúveis totais, independente da concentração da cobertura utilizada.

O minimilho obtido da cultivar de milho doce Vivi, foi mais eficiente na manutenção dos valores de acidez comparado ao minimilho obtido da cultivar de milho AG 1051, no final do armazenamento.

Houve aumento linear significativo na perda de massa de minimilho durante o armazenamento, no entanto, de um modo geral, o revestimento com cobertura de fécula de mandioca foi eficiente na preservação da massa de minimilho no armazenamento refrigerado a $5{ }^{\circ} \mathrm{C}$.

Os minimilhos obtidos da cultivar de milho doce Vivi, sem revestimento e revestidos com cobertura de fécula de mandioca a $4 \%$ apresentaram desempenho similar aos minimilhos obtidos 
da cultivar de milho comum AG1051 quanto à perda de massa no armazenamento refrigerado a $5^{\circ} \mathrm{C}$ por 12 dias.

\section{Agradecimentos}

À Embrapa Milho e Sorgo e à Universidade Estadual do Norte Fluminense Darcy Ribeiro - UENF.

\section{Referências bibliográficas}

ALMEIDA, I. P. C. et al. Baby corn, Green ear and grain yield of cultivars. Horticultura Brasileira, v. 23, n. 4, p. 960-964, 2005.

ASSOCIATION OF OFFICIAL AND AGRICULTURAL CHEMISTS AOAC. Official methods of analysis of the Association of Official Analytical Chemists. 17. ed. Washington, D.C., 2002. 570 p.

AZEREDO, H. M. C. Películas comestíveis em frutas conservadas por métodos combinados: potencial da aplicação. Boletim CEPPA, v. 21, n. 2, p. 267-278, 2003.

BOBBIO, P. A.; BOBBIO, F. O. Química do processamento de alimentos. Campinas: Fundação Cargill, 1984. 232 p.

CARVALHO, G. S. Caracterização agronômica e nutricional de cultivares de milho sob condições de cultivo para a produção de minimilho. 2002. 70 f. Dissertação (Mestrado em Agronomia)Universidade Federal de Lavras - UFLA, Lavras, 2002.

DAMASCENO, S. et al. Efeito da aplicação de fécula de mandioca na conservação pós-colheita de tomate. Ciência e Tecnologia de Alimentos, v. 23, n. 3, p. 337-380, 2003.

FAKHOURI, F. M. et al. Filmes e coberturas comestíveis compostas à base de amidos nativos e gelatina na conservação e aceitação sensorial de uvas Crimson. Ciência e Tecnologia de Alimentos, v. 27, n. 2, p. 369-375, 2007.

HENRIQUE, C. M.; CEREDA, C. M. Utilização de biofilmes na conservação pós-colheita de morango (Fragaria ananassa Duch) cv IAC Campinas. Ciência e Tecnologia de Alimentos, v. 19, n. 2, p. 231-233, 1999.

HOJO, E. R. D. et al. Uso de películas de fécula de mandioca e PVC na conservação pós colheita de pimentão. Ciência e Agrotecnologia, v. 31, n. 1, p. 184-190, 2007.

LEMOS, O. L. et al. Utilização de biofilme comestível na conservação de pimentão 'Magali R' em duas condições de armazenamento. Bragantia, v. 66, n. 4, 2007.
NERES, C. R. L. et al. Conservação do jiló em função da temperatura de armazenamento e do filme de polietileno de baixa densidade. Bragantia, v. 63, n. 3, p. 431-438, 2004.

PAULL, R. E. Effect of temperature and relative humidity on fresh commodity quality. Postharvest Biology and Technology, v. 15, p. 263-277, 1999.

PEREIRA FILHO, I. A.; GAMA, E. E. G. Avaliação de genótipos de milho em diferentes densidades de semeadura visando à produção de minimilho com maior aproveitamento comercial. Sete Lagoas: EMBRAPA-CNPMS, 2001. 4 p. (Comunicado Técnico, 29).

PEREIRA Filho, I. A.; GAMA, E. E. G.; FURTAdO, A. A. L. A produção do minimilho. Sete Lagoas: EMBRAPA-CNPMS, 1998. 4 p. (Comunicado Técnico, 7).

RIBEIRO, V. G. et al. Armazenamento de Goiabas 'Paluma' Sob Refrigeração e em Condição Ambiente, Com e Sem Tratamento Com Cera de Carnaúba. Revista Brasileira de Fruticultura, v. 27, n. 2, p. 203-206, 2005.

RODRIGUES, L. R. F.; DA SILVA, N.; MORI, E. S. Avaliação de sete famílias s2 prolíficas de minimilho para a produção de híbridos. Bragantia, v. 63, n. 1, p. 31-38, 2004.

SILVA, D. J. Análise de alimentos (Métodos químicos e biológicos). 2. ed. Viçosa: UFV, 1990. 165 p.

TOMÉ, P. H. F. Avaliação de cultivares de milho normal, doce e pipoca visando o processamento mínimo de minimilho. 2002. 89 f. Tese (Doutorado em Ciência dos Alimentos)-Universidade Federal de Lavras - UFLA, Lavras, 2002.

TOMÉ, P. H. F. et al. Processamento mínimo de minimilho. Sete Lagoas: EMBRAPA-CNPMS, 2001. (Comunicado Técnico, 32).

VICENTINI, N. M.; CASTRO, T. M. R.; CEREDA, M. P. Influência de películas de fécula de mandioca na qualidade pós-colheita de frutos de pimentão (Capsicum annuum L). Ciência e Tecnologia de Alimentos, v. 19, n. 1, 1999.

VICENTINI, N. M.; CEREDA, M. P. Uso de filmes de fécula de mandioca em pós-colheita de pepino (Cucumis sativus L.). Brazilian Journal of Food Technology, v. 2, n. 1-2, p. 87-90, 1999.

von PINHO, R. G. et al. Características físicas e químicas de cultivares de milho para a produção de minimilho. Ciência e Agrotecnologia, v. 27, n. 6, p. 1419-1425, 2003. 